\title{
Operating practices of and precautions taken by orthopaedic surgeons to avoid infection with HIV and hepatitis B virus during surgery
}

\author{
M J LeF Porteous
}

\begin{abstract}
Objective-To assess the precautions being taken by orthopaedic surgeons to avoid becoming infected with HIV or hepatitis B virus by their patients during surgery.

Design-Pilot study of 50 surgeons selected at random followed by a postal questionnaire completed anonymously.

Subjects-All 1220 fellows and associates of the British Orthopaedic Association working in the United Kingdom.

Results-800(67\%) Questionnaires were returned. 511 Surgeons has sustained a needlestick injury or had got body fluid in their eye within the past month despite 430 regularly wearing eye protection during major surgery. Seven had definitely and four possibly been infected with hepatitis $B$ virus by a patient while operating, and 582 had been immunised against hepatitis B. Only 75 surgeons were satisfied with the present guidelines on testing patients for HIV antibodies.

Conclusions-Although most surgeons who replied took some precautions when operating, most still exposed themselves to considerable risk from patients not known to be infected with HIV or hepatitis $B$ virus.
\end{abstract}

\section{Introduction}

Hepatitis B virus has been known to be a hazard to health care staff operating on or handling the body fluids of infected patients since the early $1970 \mathrm{~s} .{ }^{12}$ More recently workers have established that HIV infection may be contracted in the same way. ${ }^{3}$ Both viruses are transmitted by inoculation of infected blood or its contact with broken skin or mucous membranes. ${ }^{3}$ The risk of seroconversion after a needlestick injury with a contaminated needle has been estimated at $0.5 \%$ for HIV and $6-30 \%$ for hepatitis B virus. ${ }^{3}$ Risk factors during surgery include the perforation of surgical gloves $^{46}$ and contamination of the face with the patient's blood, ${ }^{78}$ particularly when power tools are being used.

World wide, 35 health care staff, including three

\section{Department of \\ London SE5 9RS \\ $M \mathrm{~J}$ LeF Porteous, FRCS, \\ orthopaedic registrar}

BrMed f 1990;301:167-9 surgeons, have been reported as having become infected with HIV after contact with infected blood (Dr N Gill, Public Health Laboratory Service Communicable Disease Surveillance Centre, personal communication). Several letters and articles have been published about the risks to staff, ${ }^{10-12}$ and the British Orthopaedic Association recently suggested that surgeons are becoming increasingly alarmed about the risks to which they are being exposed while operating. ${ }^{13}$ Until now, however, there has been no systematic attempt to determine the attitudes of surgeons and the precautions they are taking to avoid acquiring infections from their patients.

\section{Methods}

Six weeks before carrying out my main survey I sent a questionnaire to 50 fellows and associates of the British Orthopaedic Association selected at random; 37 (74\%) completed questionnaires were returned. On the basis of this pilot study I added two questions to the questionnaire, one asking for views on testing patients for antibodies to HIV preoperatively, and the other asking about the use of impervious gowns when operating. I did not send a second questionnaire to the surgeons questioned in the pilot study because of the similarity of the two questionnaires. I included the answers to the pilot questionnaire in the results.

I sent the modified two page questionnaire to all fellows (except honorary, corresponding, emeritus, and senior fellows) and associates of the British Orthopaedic Association living in the United Kingdom, estimating that this group included $97 \%$ of consultants and senior registrars in orthopaedics in the United Kingdom. I excluded forms returned by those working abroad or not regularly operating and entered answers from the remaining questionnaires into a computer database for analysis.

\section{Results}

Of the 1220 questionnaires sent out (including the 50 in the pilot study), $820(67 \cdot 2 \%)$ were returned. Of these, 20 were excluded from the final analysis as 16 were from retired surgeons and four from surgeons working abroad. The remaining 800 questionnaires were returned by 614 consultants, 128 senior registrars, 48 registrars, seven associate specialists, and three clinical assistants. This gave an overall response rate of $66.7 \%$. Replies came from all the health regions with only Northern Ireland (22), Wales (29), and individual Scottish health boards returning fewer than 30 . The highest return was from the West Midlands region (81), though there were 91 replies from the whole of Scotland.

Table I shows the answers to questions on operating technique and the use of impervious gowns and cotton
Do you routinely use a no touch technique?

Do you routinely use an impervious gown or plastic apron?

Do you ever wear cotton gloves while operating?

^Question not included in pilot study (37 replies). 
overgloves. Only 35 surgeons indicated that they practised all of the safest operating techniques - that is, always using a no touch technique, stitching away from themselves, and not handling suture needles with their fingers; of these, only 13 also routinely used an impervious gown. Five of the 79 surgeons who sometimes used cotton overgloves commented that they were difficult to obtain, and 18 of those who did not use them indicated that this was because overgloves were not available in their operating theatre. Altogether 384 surgeons reported having changed their operating technique or theatre rituals to reduce the risk of becoming infected while operating (table II).

Three hundred and seventy nine surgeons indicated that they had had a needlestick or similar injury while operating within the past month, of whom 104 had had such an injury within the past week. Similarly, $296 \mathrm{had}$ had contamination of the eye by body fluid during an operation within the past month, including 115 within the past week. Only 289 respondents had had neither a needlestick injury nor contamination of the eye within the past month.

Table III gives the replies to questions on the use of eye protection and the number of pairs of gloves worn when doing various categories of operation. Only 144 $(27 \%)$ of the 535 surgeons who used eye protection for joint arthroplasty reported contamination of their eyes during the past month compared with $157(59 \%)$ of the 265 who did not use eye protection. This difference (32\%; $95 \%$ confidence interval $25 \%$ to $39 \%$ ) was significant $\left(\mathrm{p}<<0.001 ; \chi^{2}\right.$ test).

Sixteen surgeons admitted to having had hepatitis B. Four did not know how they had been infected, seven had been infected by a patient while operating, and five had not been infected by a patient. Altogether $463 \mathrm{had}$ received an unsolicited offer of vaccination against hepatitis B; most of these offers (430) had come from a hospital, and the remainder had come from the respondent's general practitioner (12), a relative (four), a drug company (three), or other sources (14). Only 360 of those offered vaccination had accepted it, though most of the remaining surgeons indicated their willingness to be vaccinated if the offer was repeated.

Altogether 551 of the surgeons had been vaccinated and 31 were already immune. Of the remaining 218 ,

TABLE II -Changes made to theatre rituals and operating techniques by 384 surgeons to avoid infection with HIV and hepatitis B virus

\begin{tabular}{lc}
\hline Precaution taken & No of surgeons \\
\hline Eye protection used & $242^{\star}$ \\
Extra pair of gloves used & $194^{\star}$ \\
Impervious gown used & $40^{\star}$ \\
Extra care taken in general & 39 \\
Extra care taken with knives and needles & 17 \\
Assistant made to wear extra gloves or glasses & 15 \\
No touch technique adopted & 10 \\
Occlusive masks used & 5 \\
Handling of blood avoided & 5 \\
Operations on high risk patients avoided & 5 \\
Others & 61
\end{tabular}

«Some replies specified that these precautions were adopted only sometimes, such as for high risk patients.
164 said that they would be willing to have a vaccination and 27 that they would not (27 did not answer the question). Reasons given for refusing vaccination included fears about vaccine's safety (six), being close to retirement (five), the low rate of seroconversion in those aged over 55 (four), lack of concern (four), a fear of needles (two), and others (six), including the view that becoming infected with hepatitis B virus was "God's punishment for sloppy surgery."

Two hundred and sixty surgeons had operated on patients known to be infected with HIV; these were reasonably evenly distributed throughout the country except in Lanarkshire, where 14 of the 15 respondents had performed such operations.

Table IV shows the views on testing patients for HIV antibodies. Some surgeons answered yes to more than one part of the question, so 31 of the 75 who were satisfied with the current guidelines on testing patients also thought that all high risk patients should be tested and seven thought that all patients should be tested before surgery.

\section{Discussion}

The $66 \cdot 7 \%$ response rate to this questionnaire was disappointing, particularly after the $74 \%$ response in the pilot study, but the rate is similar to that in other postal surveys of doctors. ${ }^{14}$ Those who returned the questionnaire were more likely to be concerned about the risks of operating on infectious patients than those who did not return it, and this may have produced an element of bias in the results.

The picture presented is mixed because although half of the surgeons who replied had recently modifed their operating technique or theatre rituals and uptake of vaccination against hepatitis B was high, high rates of handling of needles, contamination of eyes, and needlestick injury remained and little use was made of the no touch technique and of double gloves, especially when operating on trauma.

The low reported rate of infection with hepatitis B virus among orthopaedic surgeons is surprising considering reports of high rates of seroconversion for hepatitis B in surgeons in the United States. ${ }^{15}$ This figure should, however, be treated with caution as many infections may be subclinical. There may also be a reluctance to report such incidents even in an anonymous questionnaire, and some of those who had had hepatitis B may have died or had to stop operating.

The high rate of vaccination against hepatitis $B$ among the surgeons $(68.9 \%)$ is perhaps the best indication of the active measures they are taking to protect themselves. The fact that only half of them had received an unsolicited offer of vaccination from their hospital and that $76 \%$ of those who had not been vaccinated would accept vaccination if it was offered to them is a serious criticism of the occupational health departments of many hospitals.

The recently enacted Control of Substances Hazardous to Health Regulations oblige employers to provide adequate protection for employees against harmful substances including micro-organisms. ${ }^{16}$ The BMA's

TABLE III -Replies given by 800 surgeons when asked about numbers of pairs of gloves and eye protection used to avoid infection with HIV and hepatitis $B$ virus during various operations

\begin{tabular}{|c|c|c|c|c|c|c|c|c|c|}
\hline \multirow[b]{2}{*}{ Operation } & \multicolumn{4}{|c|}{ No of pairs of gloves ${ }^{\star}$} & \multicolumn{5}{|c|}{ Eye protection } \\
\hline & 1 & 2 & 3 & $>3$ & None & $\begin{array}{l}\text { Corrective } \\
\text { glasses }\end{array}$ & $\begin{array}{l}\text { Non-corrective } \\
\text { glasses }\end{array}$ & Goggles & Full face visor \\
\hline High risk & 37 & 689 & 61 & 5 & 75 & 186 & 53 & 341 & 145 \\
\hline Arthroplasty & 61 & 701 & 19 & 11 & 265 & 284 & 61 & 102 & 88 \\
\hline Routine trauma & 416 & 373 & 2 & 1 & 388 & 308 & 54 & 37 & 13 \\
\hline Other major & 472 & 317 & 2 & 1 & 370 & 313 & 58 & 44 & 15 \\
\hline Minor & 736 & 56 & & & 441 & 308 & 39 & 11 & 1 \\
\hline
\end{tabular}

^Eight surgeons did not answer this question. 


\begin{tabular}{lll}
\hline & \multicolumn{2}{c}{ Answer } \\
\cline { 2 - 3 } Question & Yes No Did not answer
\end{tabular}

great care in those cases that they perceived as high risk, they still expose themselves to considerable risk from patients not known to be infected with HIV or hepatitis $B$ virus.

Do you think that:

The current guidelines that a patient's permission is always required

before he or she may be tested for HIV antibody are satisfactory?

All high risk patients should be routinely tested for HIV antibody before surgery?

All patients should be tested for HIV antibody before surgery?

\section{5}

628

672

286
97

87

112

39 Surgeons did not answer any part of the question, including the 37 who replied in the pilot study, which omitted this question; 11 answered no to all three parts of the question, and some did not answer all parts of the question.

legal department (personal communication) believes that an employer could be considered negligent for failing to vaccinate or provide proper protective clothing for its employees.

The routine use of double gloves, eye protection, and impervious gowns and immunisation against hepatitis B are simple, easily adopted precautions that considerably reduce the risk of exposure to patients' body fluids. Any further reduction in risk requires more effort by the surgeon and theatre team, particularly for those who handle needles and do not regularly practise a no touch technique. The adoption of such methods will become widespread only when surgeons perceive the risks to which they are exposed as great enough to warrant revision of their operating technique. This does not yet seem to have happened as although most of the respondents to this survey take
I thank my wife, Bridget Porteous, for her invaluable help in conducting this survey.

1 Barker LF, Shulman NR, Murray R, et al. Transmission of serum hepatitis. JAMA 1970;211:1509-12.

2 Rosenburg JL, Jones DP, Lipitz LR, Kirsner JB. Viral hepatitis: an occupational hazard to surgeons. AAMA 1973;223:395-400.

3 Centers for Disease Control. Guidelines for prevention of human immunodeficiency virus and hepatitis $B$ virus to health-care and public-safety workers. MMWR 1989;38(suppl S6):4-5, 31-3.

4 Brough SJ, Hunt TM, Barrie WW. Surgical glove perforations. Br $\mathcal{F}$ Surg 1988;75:317.

5 Hussain SA, Latif ABA, Choudhary AAAA. Risk to surgeons: a survey of accidental injuries during operations. Br f Surg 1988;75:314-6.

6 Matta H, Thompson AM, Rainey JB. Does wearing two pairs of gloves protect operating theatre staff from skin contamination? Br Med f 1988;297:597-8.

Duthie GS, Johnson SR, Packer GJ, Mackie IG. Eye protection, HIV, and orthopaedic surgery. Lancet $1988 ;$; : 481 - 2 .

8 Brearley S, Buist LJ. Blood splashes: an underestimated hazard to surgeons. Br Med f 1989;299:1315.

9 Porteous MJLeF. Hazards of blood splashes. $\mathrm{Br}$ Med f 1990;300:466.

10 Day LJ. AIDS: an occupational hazard for orthopedic surgeons? Orthop Rev 1989;18:493-7.

11 Jessop JH. Hazards of blood splashes. Br Med f 1990;300:49.

12 Sim AJW, Dudley HAF. Surgeons and HIV. BrMed $\mathcal{F}$ 1988;296:80.

13 British Orthopaedic Association. AIDS and the orthopaedic surgeon. London British Orthopaedic Association, 1989.

14 Gough HG, Hall WB. A comparison of physicians who did and did not respond to a postal questionnaire. $\mathcal{F}$ Appl Psychol 1977;62:777-80.

15 Denes AE, Smith JL, Maynard JE, Doto IL, Berquist KR, Finkel AJ. Hepatitis $\mathrm{B}$ infections in physicians. fAMA 1978;239:210-2.

$16 \mathrm{Tar}$-Ching AW. Control of substances hazardous to health. $\mathrm{Br} \mathrm{Med} f$ 1989;299:931-2.

(Accepted 20 March 1990)

\title{
Impact of childhood cancer on return to normal schooling
}

\author{
I J Larcombe, J Walker, A Charlton, S Meller, P Morris Jones, M G Mott
}

\section{Cancer Research}

Campaign Education and

Child Studies Research

Group, Department of

Epidemiology and Social

Oncology, Christie

Hospital, Manchester

M20 9QL

I J Larcombe, BSC, research assistant

J Walker, BA, research

assistant

A Charlton, PHD, director

Department of Paediatric Oncology, Royal Marsden Hospital, Sutton SM2 5PT

$S$ Meller, FRCP, consultant paediatrician

\section{Department of Paediatric} Oncology, Royal Manchester Children's

Hospital, Manchester M27 1HA

P Morris Jones, FRCP, reader in child health (paediatric oncology)

Department of Paediatric Oncology, Royal Hospital for Sick Children, Bristo BS2 8BJ

M G Mott, FRCP, reader in paediatrics (oncology)

Correspondence and requests for reprints to: Ms Larcombe.

BrMed f 1990;301:169-71

\begin{abstract}
Most of the research into the psychosocial impact of treatment for cancer in children has concentrated on effects on the family rather than on the children's return to school. Thus parents and teachers were questioned about the problems experienced by 117 children who returned to school after spending time in hospital. The children comprised 51 with cancer and two groups of control children (34 with chronic diseases such as renal disease and cardiac conditions and 32 with orthopaedic conditions such as thoracic scoliosis, club foot, and injuries resulting from trauma). Children in all three groups experienced problems on returning to school, the greatest number and variety occurring in the children treated for cancer and the fewest in the children with orthopaedic conditions. The variety of physical problems was greatest and the variety of academic problems was least, with psychological and behavioural problems intermediate. Several problems seemed to be related to drug treatment. Several children missed a considerable amount of full time education. Many teachers were unsure of the academic expectations and physical capabilities of children returning to school.
\end{abstract}

To facilitate a smooth return to school for a child with cancer improved liaison is needed between the hospital, school, and home during the child's absence and teachers need to be better informed.

\section{Introduction}

Cancer affects one in 10000 children, with about 1200 new cases occurring in Britain annually. ${ }^{1}$ In recent years developments in the treatment of child- l.ood cancer have resulted in substantial improvements in survival rates. Data from the United Kingdom Children's Cancer Study Group, which treats more than three quarters of all childhood malignancy in the United Kingdom, show a five year survival of $63 \%$ for the 1982-3 cohort of 1694 children (O B Eden, personal communication). Most children now return to school at some point during the course of their disease, many doctors recommending that they should do so as soon as possible so that at least part of their lifestyle is normal. The low prevalence of childhood cancers means that few teachers have experience of a child returning to their class after treatment for cancer, and they may be anxious because of lack of knowledge.

Extensive research has been carried out in the United States into the impact of treatment for childhood cancers on school life. ${ }^{2-5}$ In the United Kingdom most research has focused on the effects on the family rather than on the school environment. We studied problems associated with children's return to school with a view to developing material to help those concerned with this transition.

\section{Patients and methods}

We studied 117 children (51 with cancer and 66 controls) who were returning to school after spending time in hospital to identify any problems particular to children returning to school after treatment for cancer. The children with cancer consisted of 36 boys and 15 girls who had been aged 4 to 16 at diagnosis (mean age 9 years 7 months) and who were selected consecutively from ward or hospital registration lists. Children with brain tumours were excluded from the study as they present a special case and will be the subjects of a later 